\title{
Study of tsunami propagation in the Ligurian Sea
}

\author{
E. Pelinovsky ${ }^{1}$, C. Kharif ${ }^{2}$, I. Riabov ${ }^{3}$, and M. Francius ${ }^{4}$ \\ ${ }^{1}$ Laboratory of Hydrophysics and Nonlinear Acoustics, Institute of Applied Physics, 46 Ulianov Str., 603600 Nizhny \\ Novgorod, Russia \\ ${ }^{2}$ Institut de Recherche sur les Phenomenes Hors Equilibre, Parc Scientifique et Technologique de Luminy, 13288 Marseille, \\ Cedex 9, France \\ ${ }^{3}$ Department of Applied Mathematics, Nizhny Novgorod State Technical University, 24 Minin Str., 603600 Nizhny \\ Novgorod, Russia \\ ${ }^{4}$ Laboratoire de Mécanique et d'Acoustique, 31 Chemin Joseph Aiguier, 13402 Marseille, Cedex 20, France
}

Received: 1 August 2001 - Accepted: 18 October 2001

\begin{abstract}
.
Tsunami propagation is analyzed for the Ligurian Sea with particular attention on the French coasts of the Mediterranean. Historical data of tsunami manifestation on the French coast are analyzed for the period 2000 B.C.1991 A.D. Numerical simulations of potential and historical tsunamis in the Ligurian Sea are done in the context of the nonlinear shallow water theory. Tsunami wave heights as well as their distribution function is calculated for historical tsunamis and it is shown that the log-normal distribution describes reasonably the simulated data. This demonstrates the particular role of bottom irregularities for the wave height distribution function near the coastlines. Also, spectral analysis of numerical tide-gauge records is done for potential tsunamis, revealing the complex resonant interactions between the tsunami waves and the bottom oscillations. It is shown that for an earthquake magnitude of 6.8 (averaged value for the Mediterranean Sea) the tsunami phenomenon has a very local character but with long duration. For sources located near the steep continental slope in the vicinity of the French-Italian Rivera, the tsunami tide-gauge records in the vicinity of Cannes - Imperia present irregular oscillations with a characteristic period of $20-30 \mathrm{~min}$ and a total duration of 10-20 h. For the western French coasts the amplitudes are significantly less with characteristic low-frequency oscillations (period of $40 \mathrm{~min}-1 \mathrm{~h}$ ).
\end{abstract}

Key words. Tsunamis, Mediterranean, Ligurian Sea

\section{Introduction}

Although tsunamis are rather rare events for the French coasts, the catalogues of historical tsunamis of Soloviev et al. (1997) and of Tinti and Maramai (1996) show that the tsunami activity cannot be ignored for the Ligurian Sea. In

Correspondence to: M. Francius (francius@1ma.cnrs-mrs.fr) the last review paper, Heinrich (1999) has mentioned the importance of studies about the tsunami-risk for the French Rivera (Cannes-Nice). Indeed there is a relatively high tsunami activity zone, which starts at Marseilles passing along the western Italian coasts and ends at the north of the Sicilian coasts. Based on an analysis of historical information and of numerical simulations, a synthetic method is applied to investigate the characteristics of tsunami waves affecting the "Liguria-Côte d'Azur" coasts, and to give preliminary tsunami risk estimates. This study deals only with earthquake-induced tsunamis.

\section{Analysis of historical data}

Earthquakes in France are moderate and the probability that a strong destructive earthquake occurs is weak. The catalogues of earthquakes in France are summarised by Levret et al. (1994) and Lambert and Levret (1995) and Laurenti (1998). The information about tsunamis in France generated by earthquakes is rather poor. There are almost no data of tsunami run-up heights and for instance, the earthquake magnitude is known only for four events $(1564,1808,1846$ and 1887) on a total of 12 events.

Historical data and information about tsunamis in France show that from 2000 B.C. to 1991 the total number of events is 25 , but with a weak tsunami reliability value. It is important to notice that 21 of these events occurred in the 19th century. Most of the tsunamis were observed in Nice-Cannes (13 events), in Marseilles -5 events, in Sete -3 events, and the Island of Corsica -2 events. Taking into account that the first event was mentioned in 1564, the return period of tsunami for the French coast of the Mediterranean can be estimated at 18 years, as for the whole Ligurian Sea. During the 20th century there were only two events (in 1924 and 1979) that were not related to seismic activity in the Mediterranean. It is interesting to analyze the origin of historical tsunamis on the French coast of the Mediterranean. The earthquakes are 
responsible for 12 tsunamis, the submarine landslide - for one tsunami, and unknown sources - for 12 tsunamis (probably meteorological tsunamis, or local underwater landslidegenerated tsunamis).

The tsunami of 23 February 1887 is the only one with good documentation. For this tsunami, there are only two tide-gauge records, for Genoa and Nice harbors. The epicentre was located at about $20 \mathrm{~km}$ offshore from Imperia (Italy) at the bottom of the continental slope. Ferrari (1991) who calculated the seismic characteristics of this event estimated the magnitude at $6.2-6.5$. The earthquake was produced by a release of stress along the offshore normal faults oriented parallel to the coast. Parameters of the earthquake source are: strike $71^{\circ}$, dip $85^{\circ}$ (almost vertical), slip $90^{\circ}$, and displacement $35 \mathrm{~cm}$ (pure trust), length $45 \mathrm{~km}$, width $10 \mathrm{~km}$, fault center depth $10 \mathrm{~km}$. As a result, the calculated initial sea surface presents two ellipses with opposite displacements: negative - in the coastal area (less than $2 \mathrm{~km}$ of depth) and positive - in the deepest area (Eva and Rabinovich, 1997). Their numerical simulation confirmed that the first wave a point near Cannes - Genoa was negative. The second important result of the simulations is the demonstration of the resonant character of the tsunami propagation in the Ligurian Sea and of the formation of the edge waves. The amplitude comparison is not presented, but it is shown that the observed spectrum of tsunami in the Genoa harbor have the characteristic peaks corresponding to the resonance frequencies of the Genoa harbor.

\section{Mathematical model}

The nonlinear shallow-water model is used to simulate the propagation of the tsunami waves in the form of Saint-Venant equations

$$
\begin{gathered}
\frac{\partial \eta}{\partial t}=\frac{\partial M}{\partial x}+\frac{\partial N}{\partial y}, \\
\frac{\partial M}{\partial t}+\frac{\partial}{\partial x}\left(\frac{M^{2}}{D}\right)+\frac{\partial}{\partial y}\left(\frac{M D}{D}\right)+ \\
g D \frac{\partial \eta}{\partial x}+\frac{g m^{2}}{D^{7 / 3}} M \sqrt{M^{2}+N^{2}}=0
\end{gathered}
$$$$
\frac{\partial N}{\partial t}+\frac{\partial}{\partial x}\left(\frac{M N}{D}\right)+\frac{\partial}{\partial y}\left(\frac{N^{2}}{D}\right)+
$$$$
g D \frac{\partial \eta}{\partial y}+\frac{g m^{2}}{D^{7 / 3}} N \sqrt{M^{2}+N^{2}}=0,
$$

where $M$ and $N$ are the horizontal components of the discharge per unit width, $D=h+\eta$ is the total depth, $h(x, y)$ is still water depth, $\eta(x, y, t)$ is the surface displacement, $g$ is the acceleration due to gravity, and $m$ is the Manning roughness coefficient. Boundary conditions have to be added to Eqs. (1)-(3). On the open boundaries the well-known condition of the free wave propagation away from the domain is used

$$
\frac{\partial \eta}{\partial t}+\sqrt{g h} \frac{\partial \eta}{\partial n}=0,
$$

where $n$ is a normal to the open boundary. In the vicinity of the coastline (in last "sea" point) the vertical wall condition is used

$$
\frac{\partial \eta}{\partial n}=0,
$$

and the sea level oscillations are calculated along this "wall". We will assume that the "computed" tide-gauges are installed on grid points in the sea nearest to the shore, and its record will be defined as $\eta_{w}(t)$. The process of the wave run-up is not considered herein. But if we assume that the beach is a plane and the wave comes almost in an onshore direction, the run-up height can be calculated via $\eta_{w}(t)$; the review of the corresponding formulas can be found in Pelinovsky (1996). Here we will use the analytical expression derived recently by Kaistrenko et al. (1999)

$$
R(t)=\int_{0}^{t-T} \sqrt{(t-\tau)^{2}-T^{2}} \frac{d^{2} \eta_{w}}{d \tau^{2}} d \tau,
$$

where $T$ is the time of propagation from the last sea point to the shore, and $t>T$. A combination of 2D models for tsunami propagation in the open sea with a $1 \mathrm{D}$ model of tsunami run-up was checked recently using data of tsunami 12 July 1993 in the Japan Sea. This method improves significantly the agreement between computed and observed data. (Choi et al., 2000). The mathematical model described above is solved numerically by using the finite - difference scheme developed by V. Khramushin in the form of a special computer package described in book by Poplavsky et al. (1997). This package is used below to simulate hypothetical tsunamis in the Mediterranean.

\section{Source model}

Usually the choice of the tsunami source is the most complicated problem because it requires a good knowledge of the earthquake mechanism. In order to have rough estimates of the tsunami characteristics, we assumed that the initial elevation reflects instantaneously the bottom displacement. With this first approximation, the source parameters can be considered as functions of the earthquake magnitude only (see, e.g. Murty, 1977; Pelinovsky, 1996), and this is a very robust approximation.

In this paper we chose the two-parametric (earthquake magnitude and focus depth) model for the tsunami source. This model should be calibrated with local data, but these data don't exist for the Mediterranean. Therefore, we used a formula obtained for the Russian Pacific coasts where it was assumed that the tsunami source area coincides with the macro-seismic source area (Poplavsky et al., 1997). The fault 




Fig. 1. Epicentres of earthquakes induced tsunami on the French coast of Mediterranean.

length in the earthquake source $l_{0}$ is related to the earthquake magnitude $M$

$\log l_{0}=0.5 M-1.8$.

The tsunami source area has an elliptical form with characteristic lengths by

$a=\frac{l_{0}+2 h_{f}}{2}$ and $b=h_{f}$,

where $a$ and $b$ are the large and small semi-axis, and $h_{f}$ is the focal depth of the earthquake. The initial water elevation in the source is given by the empirical formula

$\log \eta_{0}=-4.31-4.36 \log h_{f}+1.45 M$.

Again, we have to note that these formulas were obtained for conditions in the Pacific, not for the Mediterranean. As a result, the calculation of absolute values of the tsunami heights is not quite correct. Nevertheless, the relation between the tsunami heights in different coastal points should be more realistic, since it depends mainly on the coastal topography and on very rough characteristics of the tsunami source, namely the source orientation.

\section{Synthetic tsunami simulation}

The evaluation of the tsunami risk for the French coast of the Mediterranean is a difficult task due to the lack of reliable data. In such cases it is possible to use the synthetic method, as seen in Curtis and Pelinovsky (1999). It is based on the wide application of numerical simulations of real events and possible tsunamis from different hypothetical sources, whose characteristics are chosen from historical data and analysis of seismicity of the given area. This approach allows one to compare the possible characteristics of tsunami in different coastal points and gives preliminary estimates of the tsunami risk. Taking into account the importance of tsunami generation in the vicinity of Nice - Imperia we perform numerical experiments for tsunami sources located along the LiguriaCôte d'Azur, at the base of the continental slope. The computational domain was defined using a 5-min bathymetry grid (ETOPO5) and a time step of approximately $9 \mathrm{~s}$ was used to integrate Eqs. (1)-(5) The numerical experiments concern epicenters located at the same place as historical earthquakes that induced tsunamis of 1818, 1831, 1854 and 1887 (Fig. 1). For prognostic modeling it is assumed that for all events the earthquake magnitude is $M=6.8$, focal depth of earthquake is $20 \mathrm{~km}$, the orientation of tsunami source is northeast, and the roughness coefficient is $m=0.0012$. According to Eqs. (8) and (9), the displacement of water surface in the tsunami source is $1.5 \mathrm{~m}$, semi-axes of the ellipsoidal source are 40 and $20 \mathrm{~km}$, consequently. The chosen source orientation is typical, for instance, for earthquakes in the northern part of the Ligurian Sea. Parameters of all events have been identically chosen mainly to demonstrate the geographical features of tsunami propagation and to compare the possible characteristics of tsunami waves all along the coasts of the Ligurian Sea.

Computed wave field is recorded in 8 points in the vicinity of the French coast (Perpignan, Sete, Marseilles, Toulon, Cannes, Nice) including the Island of Corsica (Bastia, L'ileRousse), and in 4 points of Italy (San Remo, Imperia, Savona and Genoa). Each "computer" tide-gauge is located in the "last sea point" of the computational domain (depth of about $20 \mathrm{~m}$ ). Then tide-gauge data are re-calculated for the shoreline according to Eq. (6). Spectral analysis of computed wave records was performed using the Welch's averaged method with a Hanning window having a length of 256 points and half window overlaps.

For the experiments with sources very close to Nice Imperia, the maximum amplitude $(14-29 \mathrm{~cm})$ is observed at the closest point to the earthquake epicenter (San-Remo for 
Table 1. Resonant periods (min) for the 1987 event

\begin{tabular}{cccc}
\hline Points & $\begin{array}{c}\text { Low- } \\
\text { frequency }\end{array}$ & $\begin{array}{c}\text { Middle- } \\
\text { frequency }\end{array}$ & $\begin{array}{c}\text { High- } \\
\text { frequency }\end{array}$ \\
\hline Cannes & 29.5 & 18.9 & \\
Nice & 24.6 & & 16.6 \\
San Remo & & 19.4 & 16.6 \\
Imperia & & & \\
Savona & 26.3 & 20.5 & 17.4 \\
Genoa & 26 & & \\
\hline
\end{tabular}

tsunamis 1818, 1831 and 1854; Imperia for tsunami 1887). Tsunami records of the 1818 and 1887 hypothetical events are shown in Figs. 2 and 3. Tsunami waves in Cannes Nice have amplitudes $(6-14 \mathrm{~cm})$ twice as mall as the nearest points (San Remo or Imperia) for all events. In Genoa, the wave amplitude is weak $(3-4 \mathrm{~cm})$. Because all epicenters are located very close to each other, the variation of wave amplitudes in each point for different events is weak, except for San Remo and Imperia, for which any shifting of the epicenter is comparable with the characteristic dimension of the tsunami source. Of course, absolute values of the wave amplitudes do not matter due to the idealized tsunami source, but the distribution of wave amplitudes along the coast allows one to assess the comparable damage due to tsunami at different points. In the vicinity of the earthquake epicenter, tsunami records contain, as a rule, a short intense wave train accompanied by a long oscillatory tail. In particular, the intense wave group in San Remo (event of 1818) has a duration of $1 \mathrm{~h}$, and the second crest is maximal (see Fig. 2). In Imperia (event of 1887) the maximal was the first wave, and the first three waves are intense. In all other points (or when the epicenter is not too close to the coast) each tsunami record represents the water level oscillations during 10-24h with the characteristic period of tsunami wave ranging from 20 to $30 \mathrm{~min}$ at different points. Such slow level oscillations are characteristics of abnormal tides and ebbs, and this corresponds to the description of the historical events. The origin of these oscillations is related to the resonant interaction of the tsunami waves with the bottom irregularities. There is a selective amplification of some spectral components, namely the local seiche oscillations. As a result, the characteristic "visible" period of waves in Cannes, Nice and Savona is greater than in San Remo, Imperia, and Genoa for all four events. As Fig. 4 shows, the spectral maximum varies from point to point revealing the complex picture of resonances in the basin of the Ligurian Sea. The low frequency peaks (period of 24-30 min) present in all cities except Imperia and San Remo, characterize the basin as a whole. The high frequency peaks (17-20 min) are dominant for Genoa, Imperia and San Remo. The resonant periods corresponding to the energetic peak in the spectra are given in Table 1.

The unique tide-gauge record of the 1887 tsunami at the Genoa harbour is given in Eva and Rabinovich (1997). This record shows oscillations with a height of about $10 \mathrm{~cm}$ dur-
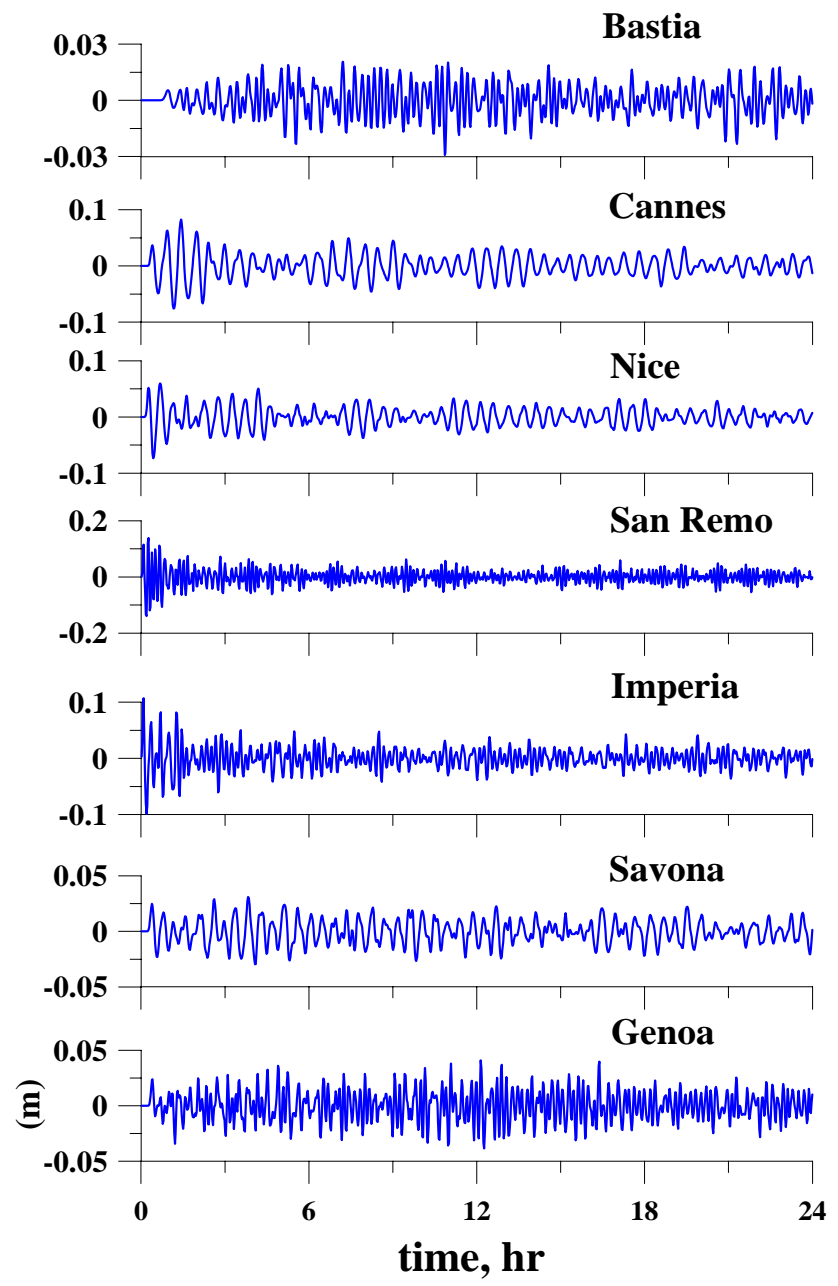

Fig. 2. Computed tsunami records for the 1818 event.

ing at least $9 \mathrm{~h}$; the characteristic period is $22.5 \mathrm{~min}$. Numerical simulation by Eva and Rabinovich (1997), who used a more realistic model for the tsunami source, explains this period as resonance period of the Genoa harbour only. Our simulations have not included the detailed characteristics of the Genoa harbour as well as the non-uniform distribution of water displacement in the tsunami source. Resonant periods of energetic peak for Genoa according to our calculations is $20.5 \mathrm{~min}$ and this value is very close to the observed period (22.5 min) and calculations by Eva and Rabinovich (1997) who obtained $22.3 \mathrm{~min}$. Also, the total duration of the tide-gauge record computed for Genoa is more than $24 \mathrm{~h}$ (observed duration is about $10 \mathrm{~h}$ ), and the waves of maximal height approach Genoa several times: 1, 5, 10, 12, 15 and $17 \mathrm{~h}$ after the earthquake. A large duration in the tsunami record is characteristic of all points of the French Rivera and this should be accounted for in tsunami warnings, and forecasting should be done at least for $10 \mathrm{~h}$ after the earthquake. Irregularity in the tide-gauge records leads to several groups of tsunami waves approaching the coast, and finally, the sea level oscillations become significant more than $10 \mathrm{~h}$ after an earthquake. This fact should be taken into account for an 


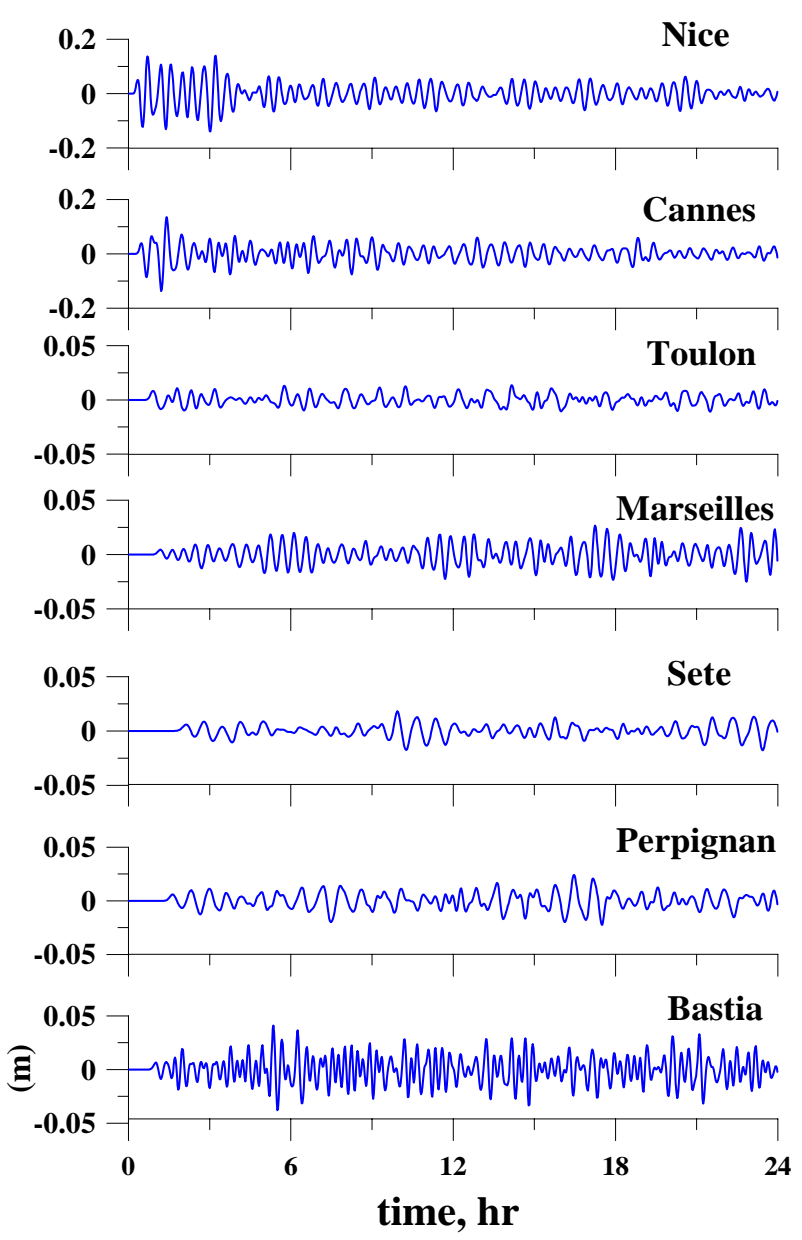

Fig. 3. Computed tsunami records for the 1887 event.

evaluation of tsunami characteristics immediately after the tsunamigenic earthquake.

The western part of the Mediterranean coast of France is protected from tsunamis generated in the northern part of the Ligurian Sea by the southern part of the French Rivera. As a result, the tsunami waves at Marseilles, Toulon, Sete and Perpignan have amplitudes approximately 5-10 times less than in Nice and Cannes. In particular, the maximal wave height in the tide-gauge record at Marseilles does not exceed $5 \mathrm{~cm}$ and this value is approximately constant for all points between Perpignan and Toulon. More important, since the travel time increases while distance from the earthquake increases, the leading tsunami wave approaches Marseilles approximately $1 \mathrm{~h}$ after earthquake, and in Perpignan $-2 \mathrm{~h}$ later. Tsunami propagates along the coast as the edge wave mainly; such waves have strong dispersion, and as a result, the most intense group reaches Marseilles 6-18 h after the earthquake. Calculated waveforms at different points in France for the 1887 event are shown in Fig. 3, and their spectra - in Fig. 4. The characteristic period of oscillation is increased with distance; in Marseilles, $26.8 \mathrm{~min}$, in Sete, $42.1 \mathrm{~min}$, and in Perpignan, $44.7 \mathrm{~min}$. It is interesting to emphasize that the spectrum of tsunami in Toulon is very wide (resonant pe-

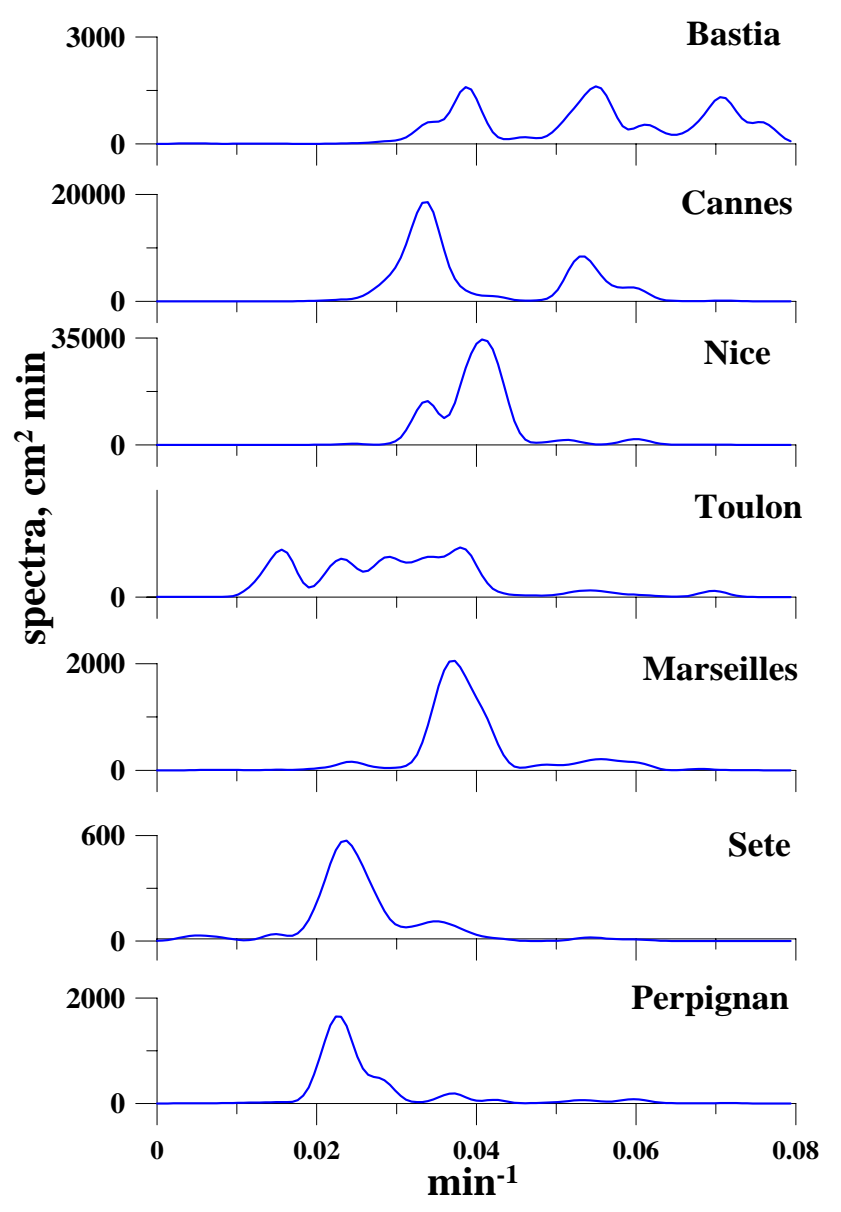

Fig. 4. Computed spectra for the 1887 event.

riod is varied from 26 to $64 \mathrm{~min}$ ). Tsunami waves in Corsica, according to our calculations, have small height (less than $8 \mathrm{~cm})$ and relative high period $(10-15 \mathrm{~min})$. The intense wave group approaches Corsica $5 \mathrm{~h}$ after an earthquake, meanwhile the leading wave $-1 \mathrm{~h}$ only.

Calculations of the vertical oscillations of the shoreline for all variants according to (9) were performed. The character of the wave profiles at the tide-gauge points and on the beach is the same. As expected, the run-up stage increases the tsunami height by 2-3 times and this is a typical value for the mean amplification factor of tsunami in the coastal zone. Of course, the calculations of the wave climbing on a beach, by using the primitive geometry only have preliminary character. In reality, much more significant amplification (of a factor 10) can be reached with specific topographical conditions in the coastal zone, namely bays and harbors. It is also important to mention that amplitude of "run-up" is approximately equal to the amplitude of "run-off". Sometimes the run-off is more significant; it occurs after the leading wave, and this correlates with many historical descriptions of tsunamis affecting the coasts of the Ligurian Sea. 

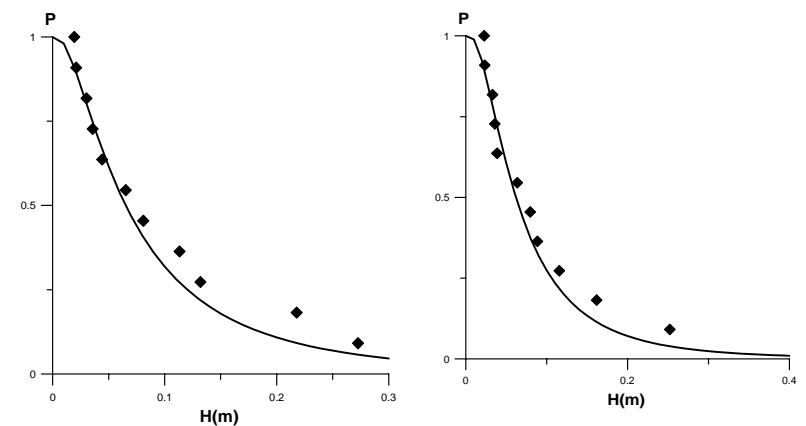

1818 Event

$N=11, a=-1.185, \sigma=0.393$

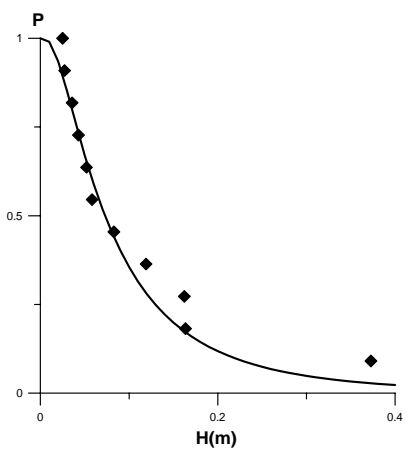

$\mathrm{H}(\mathrm{m})$

1854 Event

$N=11, a=-1.137, \sigma=0.371$
1831 Event

$N=11, a=-1.208, \sigma=0.346$

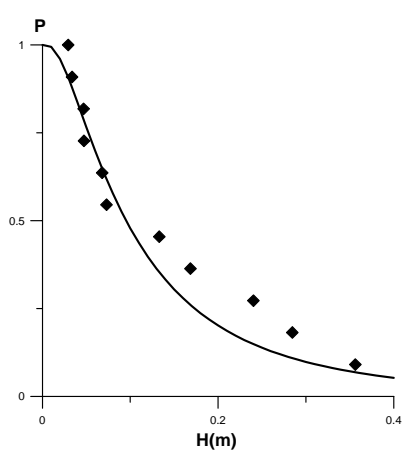

1887 Event

$N=11, a=-1.021, \sigma=0.385$

Fig. 5. Distribution functions of the computed tsunami run-up heights in the Ligurian Sea (solid line - log-normal curve; black diamonds - experimental curve).

\section{Probability distribution function}

The experimental distribution function $P(H)$ can be computed from tide-gauge records for each tsunami. To do this we use the following definition

$$
\begin{aligned}
& \text { 1, } \quad H<H_{1} \\
& P(H)=\frac{N-k}{N}, \quad H_{1}<H<H_{N} \\
& \text { 0, } \quad H>H_{N}
\end{aligned}
$$

where $N$ is the total number of measurements of wave heights of each tsunami, and $\mathrm{k}$ is the number of "random events" for which the wave height exceeds the given value or is equal to it. The distribution function is a decreasing function, $\mathrm{P}=1$ for wave heights smaller than the minimum ones observed $\left(H<H_{\text {min }}\right)$, and $P=0$ for wave heights larger than the maximum ones observed $\left(H>H_{\max }\right)$.

We compared our experimental distribution functions with the log-normal distribution. The log-normal distribution is given by Choi et al. (2002):

$F(H)=\frac{1}{\sqrt{2 \pi} 1 n 10 \sigma} \int_{H}^{\infty} \exp \left(-\frac{(\log h-\alpha)^{2}}{2 \sigma^{2}}\right) \frac{d h}{h}$,

where the distribution parameters are calculated from observable data by means of the following standard statistical

formulas

$\alpha=\frac{1}{N} \sum_{i=1}^{N} \log H_{i}, \quad \sigma=\sqrt{\frac{1}{N-1} \sum_{i=1}^{N}\left(\log H_{i}-\alpha\right)^{2}}$,

where $H$ is the run-up height, $\alpha=\langle\log H\rangle$ is the average value of the wave height logarithm and $\sigma$ is the standard deviation of the wave height logarithm. This theoretical distribution is based on the assumption that mainly the bottom relief details are responsible for the variation of the tsunami wave height variations along the coast.

Figure 5 shows that the log-normal distribution is a good model for the distribution function of the run-up heights on the shoreline. It confirms the dominant role of complex topographic features of the sea bottom, in the transformation of the tsunami waves propagating in the coastal zone.

\section{Conclusion}

The goal of this work was to characterize the tsunami manifestation on the French coast of the Mediterranean. The results of the simulation confirm the observed fact that tsunamis in France have a very local character and this is related to the relatively weak magnitudes of possible earthquakes in the vicinity of France. With the same conditions, the earthquakes in the northern part of the Ligurian Sea affect the strongest tsunami to the closest coast point. Our model is tested with data from the 1887 tsunami. The computed periods of the spectrum maxima are in good agreement with observed tide-gauge records and calculations of Eva and Rabinovich (1997). The western part of the Mediterranean coast is protected from these tsunamis by the southern part of the French Rivera. The tsunami record is represented as a long-periodic wave group everywhere with crest and trough amplitudes of the same order. Total duration of the tsunami record is about $10-20 \mathrm{~h}$ and this should be accounted for by a tsunami warning. The characteristic period of oscillations varies from one point to another point (20-30 min), but it is less for the northern part of Ligurian Sea than for the western part of the Mediterranean ( $30 \mathrm{~min}-1 \mathrm{~h}$ ). If the tsunami is generated in the vicinity of Nice-Imperia, the travel time to Nice is a few minutes for Nice and Cannes, and $1-2 \mathrm{~h}$ for the western part of the Mediterranean. Wave heights on the tsunami records are of the order of a few $\mathrm{cm}$ for the points far from the earthquake epicenter, and of the order of a few tenth $\mathrm{cm}$ in the vicinity. The climbing of the tsunami waves on a beach for the simplest geometry increases these numbers on average by a factor of $2-3$. Based on real information of the tsunami tide-gauge records and observed wave heights on the beach during the 1887 Ligurian and 1979 Nice tsunamis, the amplification factor can reach 10 at selected points. It means that the nearest earthquakes in the vicinity of CannesImperia can generate tsunami waves with maximum run-up of a few meters and induce significant damage on the coast. 
Acknowledgements. This work was done with particular support from INTAS (99-1637) and TEMPUS JRP (10460-98), and for EP and IR from RFBR (02-05-65107 and 01-05-64426).

\section{References}

Choi, B. H. Pelinovsky, E., Hong, S., and Riabov, I.: Distribution functions of tsunami wave heights, Natural Hazards, 25, 1-21, 2002.

Choi, B. H., Pelinovsky, E., Hong, S., and Riabov, I.: Simulation of historical and potential tsunamis in the East (Japan) sea, Geophys. Res. Abstracts, 2, 348, Natural Hazards, 2000.

Curtis, G. D. and Pelinovsky, E. N.: Evaluation of tsunami risk for mitigation and warning, Sci. Tsunami Hazards, 17, 3, 187-192, 1999.

Eva, C. and Rabinovich, A.: The 23 February 1887 tsunami recorded on the Ligurian coast, western Mediterranean, Geophys. Res. Letters, 24, 17, 2211-2214, 1997.

Ferrari, G.: The 1887 Ligurian earthquake: a detailed study from contemporary scientific observations, Tectonophysics, 193, 131139, 1991.

Heinrich, P.: Les tsunamis en France, Pour la Science, 260, 73, 1999.

Kaistrenko, V., Go, C. N., and Chung, J. Y.: A simple method for tsunami wave form recalculation through the shelf, IOC-IUGG Joint International Workshop on Tsunami Warning Beyond 2000 Theory, Practice and Plans, Korea, Seoul, 15, 1999.

Lambert, J., and Levret, A.: Mille ans de seismes en France, Catalogue d'epicentres parametres et references, Presses Academiques, 1995.

Laurenti, A.: Les tremblements de terre des alpes-maritimes, Histoire et sensibilisation, Serre editeur, 1998.

Levret, A., Backe, J. C., and Cushing, M.: Atlas of macroseismic maps for French earthquakes with their principal characteristics, Natural Hazards, 10, 19-46, 1994.

Murty, T.: Seismic Sea Waves: Tsunami, Can. Bull. Fisheries, Ottawa, 1977.

Pelinovsky, E.: Hydrodynamics of tsunami waves, Applied Physics Institute Press, Nizhny Novgorod, 1996.

Poplavsky, A. A., Khramushin, V. N., Nepon, K. I., and Korolev, Yu. P.: Short-term forecasting of tsunamis on the sea coasts of the Far East of Russia, Institute of Marine Geology and Geophysics, Yuzhno-Sakhalinsk, 1997.

Tinti, S. and Maramai, A.: Catalogue of tsunamis generated in Italy and in Côte d'Azur, France: a step towards a unified catalogue of tsunamis in Europe, Annali di Geofisica, 39, 1253-1299, 1996.

Soloviev, S. L., Go, Ch. N., Kim, Kh. S., Solovieva, O. N., and Shetnikov, N. A.: Tsunamis in the Mediterranean sea 2000 B.C.1991 A.D., Moscow, Institute of Oceanology, 1997. 